\title{
Barriers To B2C Segment Of E-Business
}

M. B. Khan, (E-mail: mkhan@ csulb.edu), California State University, Long Beach

Merle Martin, (E-mail: martinmp@csus.edu), California State University, Sacramento

\section{Introduction}

Computer technologies have changed the way business is transacted. Business-to-business (B2B) transactions have been transmitted electronically through the Electronic Data Interface (EDI) for almost twenty years, thus relegating this paradigm to a mature technology category. Introduction of the Internet has enhanced the B2B segment, but has enabled business-to consumer (B2C) commerce even more. The volume of business on the Net is exploding and is projected to continue to grow exponentially. This volume is expected to reach much as $\$ 8$ trillion by 2004 (6).

Adoption of the B2C segment, however, is projected to grow at a slower rate than the B2B segment, dropping from 20 percent of the total to a projected 10 percent in the next few years (6). This lagging B2C segment growth has been fed by a high rate of failure for dot.com companies providing Internet goods and services. As one business analyst stated, "Internet analysts predict that in the next three years between 60 to 90 percent of all dot.com retailers, regardless of how much money they start with or who's backing them, will go out of business." (5)

There is little doubt that poor business planning and practices have accounted for many of these dot.com failures. There are, nevertheless, other reasons such as investment impediments and cultural adoption resistance. Primary among these failure causes are current technological barriers /encompassing both computer hardware and software. These barriers include system security and reliability, user interface design, processor speed, bandwidth, sound and picture quality, and virtual ("try-on") immaturity.

The purpose of this paper is to identify several barriers affecting B2C segment growth and to project technological advances that may soften or eliminate these barriers. Included in the paper is an analysis of the interrelationship between barriers and products. Finally, the paper presents the impact of technology-controlled and human-controlled factors on Internet sale.

\section{Cultural and Investment Barriers}

Several non-technological factors have contributed to the slowed growth of the B2C segment. These include (1) B2C immaturity, (2) cultural barriers, (3) investment pressures, (4) the lengthy E-Business marketing cycle, and (5) the discontinuous nature of the technology adoption life cycle.

B2C Immaturity: The B2C segment of E-Business is not a mature technology paradigm as is its B2B counterpart. Most B2C companies have not had the time to progress through Dent's "E-volutionary Curve" of automation, reengineering, enterprise modeling, and fashioning of alliances (3). These firms have plunged into the cyberspace market without the opportunity to polish and perfect their product and service offerings. The result has been a lower than expected percentage of repeat customers.

Cultural Barriers: B2C faces several cultural problems not associated with the B2B segment of E-Business. These include (a) uneven access, (b) a "try on" mindset, and (c) the brick and mortar institution as a means of social interaction. Schneiderman (11) cites as one of his ten information age plagues the development of technology "haves" and "have-nots." B2C requires an extended technology interface that may not be equally available to all demographic groups. A recent study demonstrated this phenomenon in play within our schools, where the extent of computer and Internet access was directly related to economic differences (12)

The "try-on" mindset applies to most products and services that are not digital in nature. Consumers hesitate to buy clothes, cars, or other tangible goods unless they have the opportunity to see how it fits, or to "kick 
the tires". Finally, many consumers consider shopping as more than a means of securing goods or services. These consumers value shopping as a social experience - an opportunity to interact with other human beings.

Investment Pressures: Most dot.com companies have relied on securing seed money from capital entrepreneurs. Many of these investment entities have sponsored multiple dot.com initiatives in the hope that one or two of these prospects will "make it big". Some firms use a portfolio investment strategy whereby investments occur in stages with less likely prospects falling out at each investment stage (7). What has happened, however, is that the investment cycle has been decreasing. This cycle measures the time from initial investment until the new company goes public (IPO) or is acquired for a profit by another firm. This cycle has decreased in the past few years from as long as three years to as little as 18 months. Thus B2C dot.com companies now have less time to become successful before funding lapses.

E-Business Marketing Cycle: This reduced investment cycle is accentuated by the lengthy marketing cycle facing B2C firms, particularly those that are new to the market. Davis and Meyer (2) describe the Internet Marketing cycle as including these steps: (a) Let consumers know that you are on the Internet and where to find you. (b) Encourage consumers to visit your site. (c) Encourage consumers to buy something. (d) Satisfy consumers so that they will revisit your site. and (d) Increase the volume of sales to the point where you are making a profit. Experienced B2C firms such as Amazon.com have reached the final stage only recently. In many dot.com cases, the shorter investment cycle has expired before the new company had the opportunity to progress past the first two or three steps in the EBusiness marketing cycle.

Technology Adoption Life Cycle: Moore suggests that adoption of discretionary (non-mandatory) technology follows a specific life cycle (10). In Moore's life cycle, two groups adopt new technology paradigms rather quickly. These groups include Early Enthusiasts and Early Pragmatists. The Early Enthusiasts are excited about any new technology and will rush to try it. The Early Pragmatists see immediate economic benefits in the new technology paradigm and wish to "strike early" to take advantage of these benefits. Between these two groups and the remaining groups of technology adopters is what Moore calls the "chasm". It is a period of delay (resistance) until the new technology paradigm is complete, of high quality, and thoroughly tested by the first two adopting groups. Thus, new B2C firms might expect an initial consumer rush toward their offerings (first two groups) followed by stagnation until the offering is proved to remaining groups of consumers.

These forces interact to create a landscape conducive to B2C firm tardy successes and early failures (Exhibit 1). There are, however, several technologically oriented problems as well.

\section{Technological Barriers}

There is no doubt that technology is the driving force behind E-commerce. However, it is the same technology that stands in the way of increased activity in e-commerce. A review of market findings will reveal certain products as being "hot" on the Net while others are not. While price may be a major factor in this determination, there are technological barriers that are equally responsible as to why certain items do not sell on the Net as well as others do. These technological barriers fall into either hardware or software (a few may be in both categories) and are identified as being the following.

Bandwidth: The transmission capacity of a communications channel is a major technological barrier for products that require more graphics than textual data. Products with intricate design details are specially worth mentioning. Jewelry, clothes with handmade works, decorative items, and the like fall in this category.

Broadband channel is a relatively new technology. If this technology can be affordably piped into every home making interaction with the Internet far richer, sale of products requiring graphics will rise significantly. 


\section{Exhibit 1 B2C Forces}

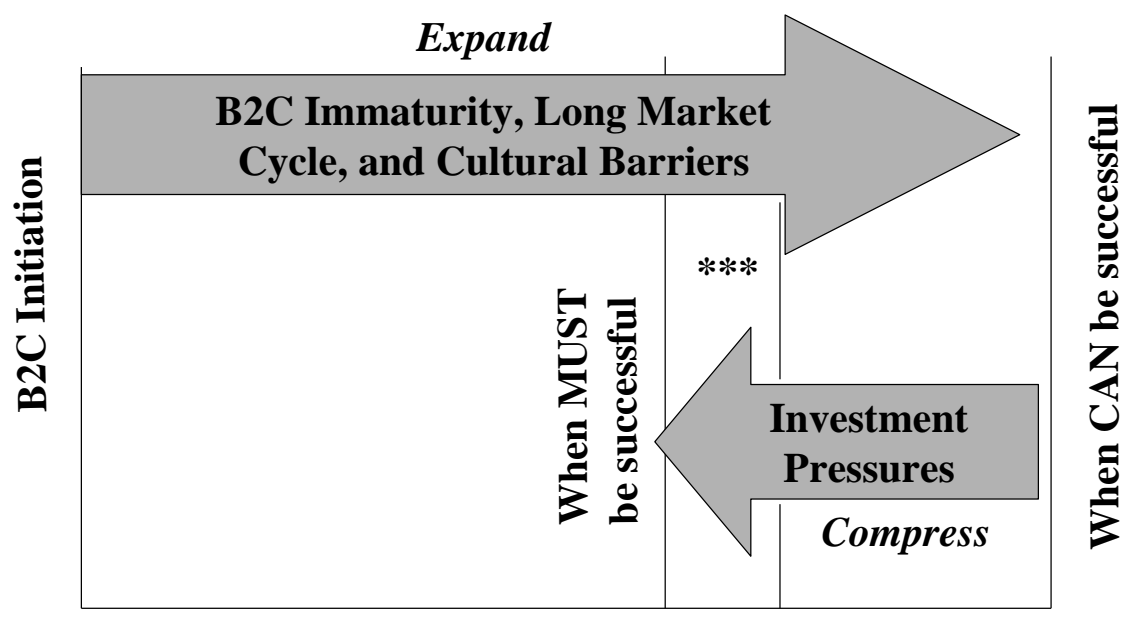

\section{B2C Development Time}

*** Moore's "Chasm"

Processor Speed: Processor speeds are increasing at an exponential rate. With this increase in speed, user expectations have risen. All of us want a faster processor; even the fastest computer seems slow at times. A customer trying to buy a product online does not want to wait as a computer retrieves a picture of the product and displays it on the screen. In an off-line mode, users do not care so much if the system is slow because they are conditioned to that slowness; they are not connected to a computer. Processor speed becomes paramount when customers want to see competitive products simultaneously.

System Security: Security on the Internet poses a special impediment. No user will interact with the Net if it does not guarantee 100 percent security. Users expect a higher degree of security on the Internet than they do for other transaction media such as the telephone. Such security involves protection of user identity and safeguard of user's credit card information. A large number of studies show that consumers are quite apprehensive about communicating credit card information over the Internet (4). This apprehension is not totally related to the monetary amount involved in a transaction as much as to the fact that it puts the consumers at risk of losing money via credit card fraud. Many Internet channels are quite open and susceptible to unscrupulous tapping and tampering.

System Reliability: System reliability is as important as system security. If the Internet is unavailable due to hardware, software, or transmission problems, on-line sale of products will suffer. Too many Net failures will finally lead to user dissatisfaction and may even result in total withdrawal. While experienced users of the Net will tolerate occasional system failures, novice users will withdraw from the Net if such system failures occur during their earlier "experimentation" phase. These novice users will question the credibility of the system.

Sound and Picture Quality: Sale of certain products on the Net is dependent on sound and picture quality. For example, stereo speakers will not sell if sound quality on the Internet is not high. Similarly, products that are "lookcentered" will sell poorly if picture quality is bad. Lipsticks, intimate apparels, sunglasses, wristwatches, jewelry, and others fall in this category of products.

User Interface Design: Now more than ever, the promise of electronic commerce and online shopping will depend to a great extent upon user interface design and how people interact with computers. Limited menus, poorly designed navigation, and the difficulty in comparing multiple products on the same screen all have adverse effects 
on electronic shopping (8). Studies have identified a list of user interface design attributes that influence online store traffic and sales. Among these attributes are: variety of merchandise, service, help with product selection, system response, promotion, advertising, convenience, checkout, and store navigation.

One study has examined the idea that web page design can change customer preferences by influencing attribute importance (10).

Virtual Immaturity: There are products that most customers will hesitate to buy unless they can touch, feel, and try-on. Clothing, sunglasses, wristwatches, lipsticks, handbags, shoes, cologne, make-up items, and are examples. Technology cannot yet offer the touch/feel experience. However, technology will be able to provide online try-on that will increase sale of clothing. Clothing items are currently being sold on the Net without an online try-on feature. These items are standard clothing products that are well known to customers and do not require online tryon. Generally, these products are inexpensive (less than $\$ 50$ or so). However, expensive products such as suits, jackets, and the like will not sell in great quantity on the Net unless technology features online try-on. Current hardware technology permits such try-on; however, appropriate software does not exist.

There are products that will probably be sold only rarely on the Net. These are expensive items such as automobiles, diamonds, expensive watches/jewelry, and the like. Customers most likely will use the Internet to research such products and then visit a brick-and-mortar store for the actual purchase.

Exhibit 2 lists the technological barriers, barrier types and products affected by these barriers.

Exhibit 2 Technological Barriers and Products Affected

Barrier

Bandwidth

Processor Speed

System Security

System Reliability

Picture Quality

Sound Quality

User Interface Design

Virtual Immaturity
Type of Barrier

Hardware

Hardware/Software

Software

Hardware/Software

Hardware/Software

Hardware

Software

Software
Products Affected

Jewelry, special clothes, decorative items Comparative products

All products

All products

Jewelry, watches, television

Stereo speakers

All products

Automobiles, expensive clothes, jewelry

\section{Potential Technological Advances and Their Impact on Internet Sales}

Hardware advances will continue to outpace those in software. However, advances in both hardware and software are essential to increase customer confidence and thus increase sales on the Net. In this section, we identify some potential advances that will have a positive impact on Internet sale.

Bandwidth: Bandwidth technology will continue to improve. The transmission capacity of a communication channel will increase, as will be its reliability. Both improvements will contribute to Internet sale.

Processor Speed: If Moore's Law continues to hold true (and there is some doubt that it will), processor speed will be faster and faster. This will decrease users' wait time and consequently increase their satisfaction and confidence in online sale. With the improvement in processor speed, competitive products can be shown simultaneously making Internet sale more appealing.

System Security/Reliability: Newer protocols will be developed to provide security and privacy in electronic transactions. These protocols will be less complex and will have faster response time. 
Newer software products have started emerging that addresses the myriad security-related problems facing the Internet, such as content piracy, privacy, secure e-commerce, virus attacks, transaction scalability, and the dynamic changes in security approaches. Also included in these products are marketing and sales activities for smart cards, smart-card readers and security software (11).

Sound/Picture Quality: Improvements in sound and picture quality will continue to be made. Consequently, increasing sale of certain items on the Net can be expected. For example, with better sound quality, sale of stereo speakers will increase. Better picture quality will increase sale of fine intricate fashion items such as jewelry.

User Interface Design: As we understand more and more the way humans interface successfully with computers, better user interfaces will be designed. Significant improvements will occur in this sphere in the future. Such improvements will benefit all customers, especially novice users.

Virtual Immaturity: This is an area in which much progress may not take place. Online try-on features are technically feasible, but they may not be economically feasible for many years. Development of software for online try-on capabilities will require revolutionary paradigms

\section{Technological Controls Versus Human Controls}

Sale of goods on the Internet depends on two factors, partially technology-controlled and partially at the control of humans. Technology can make a customer buying process more convenient, but convenience alone will not attract customers to buy on the Net. Customer confidence plays an equally important role. If customers do not feel confident about buying a product, they will not buy that product regardless of the level of convenience. Price is another factor. Whether a price is high, reasonable, or low depends on the financial condition and personal preference of a customer. Price of a product can be controlled to some extent by technology; however, human perception is the dominant factor.

The interrelationship between customer convenience and customer confidence and their impact on Internet sale is depicted in Exhibit 3. Products falling in the high convenience and high confidence area will have high sale potential. Take the example of travel. Arranging travel through the Internet has both a high level of convenience and confidence and thus has become the largest online sale item. Products falling in the low convenience and low confidence area will have low sale potential. There are not too many items that fall in this category since technology always increases convenience. High convenience but low confidence items will also have low sale potential. Examples are real estate, cars, and jewelry. In a survey conducted by the Graphics, Visualization, and Usability (GVU) Center at Georgia Tech (6), only 1.6 percent of respondents reported buying jewelry on the Net (for expensive jewelry, this number will be far less); 2.0 percent indicated they bought real estate, and 4.3 percent reported buying autos. Products with high confidence and low convenience are questionable sale potential. Other products can be cited falling in each of the four quadrants of the graph.

Exhibit 3 Interrelationship between Convenience and Confidence and Impact on Internet Sale

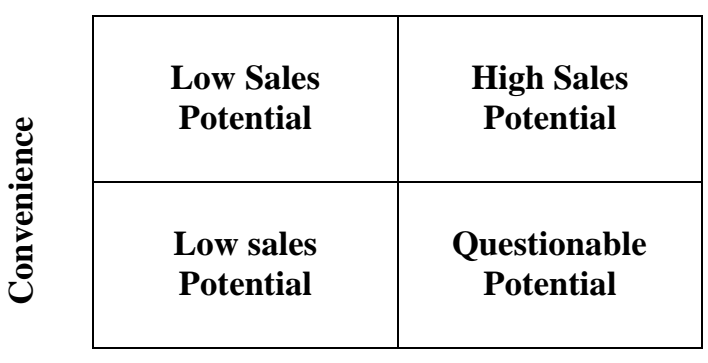

Consumer Confidence 
Exhibit 4 shows the interrelationship between confidence and price and their potential impacts on Internet sales.

Exhibit 4 Interrelationship between Confidence and Price and Their Impact on Internet Sales

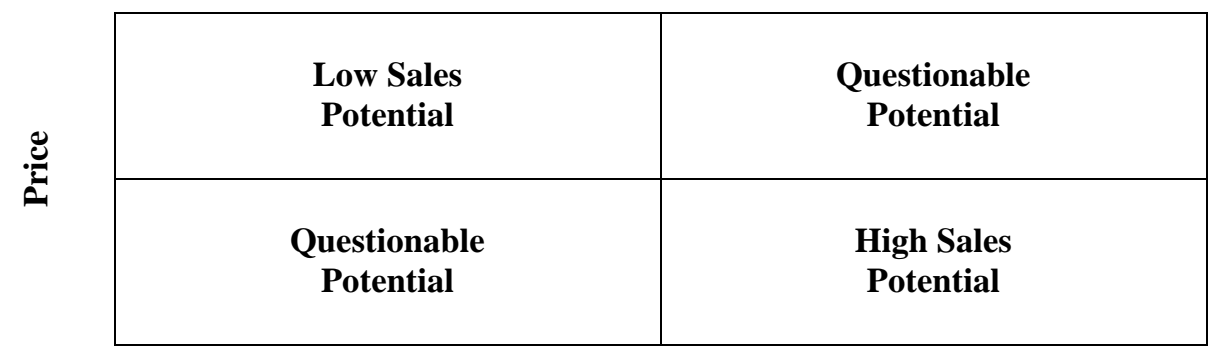

Consumer Confidence

Products that are high in price but have low customer confidence will not attract customers. On the other hand, items that are low-priced but enjoy high customer confidence will be easy to sell on the Net. Low-priced products with low consumer confidence and high-priced products with high level of customer confidence have questionable sale potential.

\section{Conclusion}

Technological barriers have an influence on the sale of goods on the Internet. This paper has identified several of these barriers. Over time, advances in technology will reduce the impact of many of these barriers and Internet sales will increase. Once these barriers are removed, B2C activity should reach the commodity stage and increase at an even faster rate than it is increasing today.

Products that will increase in sales are either digitized products (e.g. computer hardware/software, CDs, videos/movies, etc) or inexpensive items (such as jeans, T shirts, movie tickets, etc). Some of these products could fall in both categories. For these products, both convenience and confidence levels are high.

Certain products probably will sell only rarely on the Net regardless of technological maturity and customer familiarity with the computer technology. Most customers will not have the comfort/confidence level necessary to buy such products on-line. For these products, convenience will never outweigh the inherent risk. In such cases, the Internet will continue to serve as a research or advertising medium rather than as a virtual store where business transactions take place.

Critical success factors for the B2C segment of electronic commerce include convenience, risk, affordability, user interface, and legal/regulatory considerations. Some of these factors are controllable by technology while others are not.

This research will have some marketing implications. It allows marketers to decide on how to spend their advertising dollars on different items. Designing better and more expensive Web pages for those products that will rarely sell on the Internet will not result in high pay-offs and thus such efforts should be avoided.

\section{References}

1. Bhatnager, A. Misra, S. \& Rao, H.R. On Risk, Convenience, and Internet Shopping Behavior. Communications of the ACM 43, 11 (Nov, 2000), 98-105.

2. Davis, S. and C. Myer; The Blur; (Warner Business, 1999) 
3. Dent, H; The Roaring 2000's; Simon \& Schuster, 1998)

4. Fram, E.H. \& Grady, D.B. Internet Shoppers: Is there a surfer gender gap? Direct Marketing 59, 9 (Jan. 1997), 46-50.

5. $\quad$ FOX Market Wire $(1 / 18 / 01)$

6. Gartner Group

$7 . \quad$ GVU Center's $10^{\text {th }}$ WWW User Survey. Georgia Institute of Technology (1998).

8. $\quad$ Lucas, H; Information Technology and the Productivity Paradox; (Oxford, 1999)

9. Lohse, G.L. \& Spiller, P. Electronic Shopping. Communications of the ACM 41, 7 (Jul, 1998) 81-87.

10. Mandel, N. Constructing Preferences Online: Can Web Pages Change What You Want? Unpublished paper. The Wharton School, University of Pennsylvania (Feb, 1999).

11. Mokhoff, N. Net Solution Tackles E-Commerce Security. Electronic Engineering Times (Nov, 2000).

12. Moore, G; Crossing the Chasm; (Harper Business, 1995)

13. Shneiderman, B; Designing the User Interface; (Addison Wesley, 1987)

14. _ _ _ Falling Through the Net: Defining the Digital Divide; US Department of Commerce, 7/99)

Notes 
Notes 